\title{
Monopsonistic Competition for the "Best" Workers
}

\author{
Fabio Fiorillo /Stefano Santacroce /Stefano Staffolani \\ Department of Economics - University of Ancona*
}

8 settembre 2000

\begin{abstract}
Sommario
In this paper we analyse an economy where firms use labour as the only production factor, with constant return to scale. We suppose that jobs differ in their non-wage characteristics so each firm has a monopsonistic power. Mainly, we suppose that workers are heterogeneous with respect to their productivity. Then, each firm has incentives to offer higher wages in order to recruit the most productive workers. The competition among firms leads to a symmetric equilibrium wage which is higher than the reservation wage and to involuntary unemployment for the less productive workers, that are willing to work at the current wage but are not hired because their productivity is lower than the wage level. If firms have no institutional constraint on paying lower wages for the same job, an endogenous labour market segmentation emerges.
\end{abstract}

\footnotetext{
Departement of Economics -

Via Birarelli 11

60121 Ancona

tel +39 712203901

Email: Staffolani@deanovell.unian.it
}

This research is financed by CNR. We thank R. Martel, R. Lucchetti, R. Balducci and the partecipants to 12 AIEL (Associazione Italiana Economisti del Lavoro) for suggestions; all remaining errors are ours. 


\section{Introduction.}

The management of human resources becomes more and more important if workers have not the same individual characteristics, as in the Weiss ${ }^{1}$ efficiency wage model or in the Manning's 'Company Wage Policies' model ${ }^{2}$, where workers differs in their productivity level and in their relative valuation of leisure, given a scenario where firms must pay the same wage to all workers. Actually, heterogeneity is not a new feature in this subject. It seems rather to be an implicit concept shared by most unemployment theories, kept hidden for the sake of simplicity, or, more provocatively, not to invalidate some of the results.

The main assumptions in our model are that workers have the same reservation wage, but they differ in their productivity level ${ }^{3}$.

Moreover, they earn the same wage if employed in the same firm. There are reasons tha can justify the rule "one job, one wage". As Manning ${ }^{4}$ wrote:

"... seemingly identical workers receive different rewards depending on who they work for ... many firms (both union and non-union) seem to have less variation in wages among workers doing a particular job then there are differences in productivity and this seems to be known to the employer. ... It would seem that wages are often attached more to the firm ... than the individual.".

A second group of hypotheses concerns the demand side of our labour market. In this economy firms have a certain monopsonistic power depending upon their job characteristic as in the recent article by Bhaskar and $\mathrm{To}^{5}$ :

"Different jobs have non-wage characteristic, giving each employer market power in choosing the wage, even though she employs only a small fraction of work force.".

As in their paper we suppose that firms are spatially differentiated ${ }^{6}$, thus workers incurs travelling expenses.

\footnotetext{
${ }^{1}$ Weiss, 1980.

${ }^{2}$ Manning, 1993.

${ }^{3}$ In Weiss's model (1980) workers differ in reservation wage that is positively correlate with productivity. As Rebitzer (1989) notes this assumption holds if "a large, non industrial sector of self-employed craftmen, professional and casual labourers" exists. On the contrary Weiss's model disintegrates.

${ }^{4}$ Manning, 1993, p. 1. See also the "gift exchange economy" described by Akerlof (1982) and the "social status"considerations proposed by Frank (1985)

${ }^{5}$ Bhaskar and To, 1996.

${ }^{6}$ We utilise the hypothesis of spatial differentiation of firms for simplicity's sake; the analysis presented in this paper may also be applied in every setting in which each firm offers different non-wage characteristics of jobs to its workers.
} 
The workers and jobs heterogeneity hypothesis leads firms to compete in order to hire the best workers, offering a wage higher than the market clearing one.

Contrary to labour market perfect competition models, firms do not face perfectly elastic labour-supply schedules. Small changes in wages do not produce infinite changes in the available supply of labour. In fact, the presence of travelling expenses makes workers move subject to a cost-benefit calculus.

In order to maximise profits, each firm could offer above-average wages. In this way it raises the dimension of labour force that would like to work for the firm, i.e. it enlarges its basin of attraction, widening the range of the bowl from which selecting the best workers. Under certain conditions, we demonstrate how firms will hire only those applicants whose productivity level is higher than the offered wage.

Following this way, it is possible to calculate a sort of reaction function for each firm, whose wage will depend on the average wage paid in the industry. A symmetrical steady state equilibrium emerges from this framework, characterized by a wage higher than the market clearing level. Let us call this kind of labour market as monopsonistic competition.

A simple example will help to understand our model. Let us suppose that in an economy there are two firms and four workers. Firms have perfect knowledge of workers' productivity and operate with constant return to scale. Workers' reservation wage is $v=1-\varepsilon$, with $\varepsilon$ infinitesimal. Moreover, two of the workers are "good" ones and produce two units of output each day. The other two are "bad" and produce only one unit of output each day. Each firm may pay a wage $v$, or it can choose to pay a wage $w>v=1-\varepsilon$. If firms pay the reservation wage, all workers are employed.When firms pay the same wage, their labour force is composed in the same way. If the two firms pay $v$, the profit of each firm is: $\pi_{v, v}=(1-v)+(2-v)=1+2 \varepsilon$. When both pay $w>v$ the "bad" quality workers will be unemployed, and each firm has a profit: $\pi_{w, w}=2-w$. When firm 1 pays $w$ while firm 2 pays $v$, firm 1 can hire the two "good" workers obtaining a profit of: $\pi_{w, v}=2(2-w)$, while the other firm employs the bad workers and obtains $2 \varepsilon$. The opposite is true when firm 2 pays $w$ and firm 1 pays $v$.

In this simple game (à la Bertrand), the optimal strategy $(v, v)$ is dominated by the Nash equilibrium $(w, w)$ :

table 1 about here

Therefore firms will pay a wage which is higher than the reservation wage and a part of the labour force will be unemployed. Note that it is rational for each firm to raise its wage over the wage $w$ paid by the other. So, in this case the wage equals the productivity of the best workers $(w=2)$ and profits are zero.

In the next sections we will present a model to grasp the main issues of this introduction. The model is presented in a context of perfect information. This is one 
of the major simplifications of our model, and it implies that, when unemployment exists, people without job are those with a lower productivity level.

Section two will introduce the main characteristics of the model in two different cases: when firms do not compete for workers (monopsony with heterogeneous workers) and when firms act as monopsonistic competitors for the best workers; in section three we will suggest an alternative functioning of this kind of labour market introducing the possibility of labour market segmentation. Section four is devoted to some concluding remarks.

\section{The model}

In our model, workers are located around a ring, as in figure 1, where the whole population $(P)$ lives. Around this ring there is also a certain endogenous number of firms $(J)$, which produce an homogeneous item in a perfectly competitive goods market. So jobs are differentiated by their location ${ }^{7}$.

figure 1 aroud here

Thus each firm chooses his workers within a limited area of the ring. Let us define $\left(L_{j}\right)$ as the labour supply attraction basin of the $j-t h$ firm.

We suppose that workers are heterogeneous with respect to their productivity $(\lambda)$; this means that for a given job, there are workers capable of producing higher output $^{8}$. We assume that this productivity is uniformly distributed, so the number of workers for each level of productivity is

$$
\mu=\frac{1}{b-a} P
$$

where $b$ and $a$ are respectively the maximum and the minimum productivity level, and $P$ is the population.

Assuming constant return to scale, profits of the $j-t h$ firm are given by:

$$
\pi_{j}=\left(1+\sigma_{j}\right) \lambda\left(w_{j}, w\right) n\left(w_{j}, w\right)-n\left(w_{j}, w\right) w_{j}-F
$$

\footnotetext{
${ }^{7}$ In a more general setting, we could suppose that workers prefer a particular firm in relation to the characteristics of the job offered by the firm. Therefore in our model the spatial localisation is simply a metaphor of job differentiation.

${ }^{8}$ In the famous article "Labour contract as a partial gift exchange" George Akerlof reported the Homans study on cash posters productivity. He showed that the performance of cash posters varied between 306 and 439 cards per hour, and, even if output was easily observable, all cash posters gain the same wage. Empirical evidence of different productivity levels between workers that are paid the same wage is a common phenomenon and is well documented in the literature of human resources management.
} 
where $\sigma_{j}$ is an idiosyncratic shock with mean equal to zero, $w_{j}$ is the wage paid by firm $j, w$ is the outside wage, $\lambda$ is the average productivity of labour, $n$ is employment in the firm and $F$ are exogenous fixed costs.

Employment and average productivity depend both on wage paid by firm $j$ and on wages of other firms. Firm $j$ maximises its profits choosing the wage $w_{j}$ defined by:

$$
\left(1+\sigma_{j}\right)\left[\lambda_{w_{j}} n+\lambda n_{w_{j}}\right]=n_{w_{j}} w_{j}+n
$$

The employment at firm level $\left(n_{j}\right)$ is constrained by the labour force that each firm may find on the market $\left(L_{j}\left(w_{j}, w\right)\right)$.

All workers are willing to work if the wage $(R)$ is bigger enough to cover the reservation wage plus the travelling expenses $\left(\frac{\alpha}{J}\right)^{9}$, where $\alpha$ is the travelling cost per unit of distance. So labour force $(L)$ is less than population $(P)$ if:

$$
w<\frac{\alpha}{J}+R
$$

If condition 4 holds each firm acts as a pure monopsonistic one since the attraction basins of two contiguous firms do not overlap, otherwise each firm interacts with others in a monopsonistic competition framework.

Let us examinate the two cases separately.

\subsection{Monopsony with heterogenous workers}

If condition 4 holds, for some workers it is not convenient to participate to the labour market. In order to calculate the labour force available to the firm ${ }^{10}$, that is the geographic basin of attraction of firm $I_{1}$, let us focus on the worker on point $A$ of figure 1 for whom it is indifferent to work in firm $I_{1}$ or to not participate to the labour market.

For this worker, the following equation must be valid: $w_{1}-\alpha 2 \overline{I_{1} A}=R$. We can also write $\frac{w_{1}-R}{\alpha}=2 \overline{I_{1} A}$.

Then it is not difficult to look at $\left(2 \cdot \overline{I_{1} A}\right)$ as the geographic basin of attraction of firm $I_{1}$. If the workers are uniformly distributed around the ring, the following ratio must be valid: $2 \overline{I_{1} A}: 1=M_{1}: P$, where $M_{1}$ are those workers attracted by the monopsonistic firm $I_{1}$. Substituting $2 \overline{I_{1} A}$ and generalizing for firm $j$, we obtain the available labour force for firm $j$ :

$$
M_{j}\left(w_{j}\right)=\frac{w_{j}-R}{\alpha} P
$$

\footnotetext{
${ }^{9}\left(\frac{\alpha}{J}\right)$ is the travelling expense of the farest worker.

${ }^{10}$ It is reasonable to imagine that the distance between two contiguous firms is constant.
} 
We suppose that firms have perfect knowledge of workers' productivity. Thus, for a given level of wage, firm $j$ will employ all workers of its attraction basin with productivity higher than the wage. Clearly the attraction basin is increasing on the wage paid by the firm. Thus, integrating equation 5 from $w_{j}$ to $b$, we obtain the employment in the $j-t h$ firm $n\left(w_{j}\right)$

$$
n_{j}\left(w_{j}\right)=\int_{w_{j}}^{b} \mu \frac{M_{j}\left(w_{j}\right)}{P} d \Lambda=\mu \frac{w_{j}-R}{\alpha}\left(b-w_{j}\right)
$$

which is increasing in $w_{j}$ until $w_{j} \leq \frac{b+R}{2}=\widehat{w}_{j}$ (see figure 2). It is important to realize that the wage is not only a variable cost, but also a strategic tool to force the firm's average productivity, because output and employment are a function of the wage.

figure 2 about here

The unemployment rate, obtained from equation 5 and equation 6 :

$$
u=1-\frac{n_{j}\left(w_{j}\right) J}{L_{j}\left(w_{j}\right) J}=1-\frac{b-w_{j}}{b-a}
$$

is increasing in $w_{j}$ because the labour force increases faster than employment.

Proposizione 1 In a monopsonistic economy characterized by workers with equal reservation wage but different labour endownements, involuntary unemployment exists

Unemployment exists because firms raise the wages above the equilibrium level in order to enlarge their basin of attraction and to hire the most productive workers.

For a given number of firms $(J(w)=J)$ the partecipation rate is:

$$
p=\frac{L_{j}\left(w_{j}\right) J}{P}=\frac{w_{j}-R}{\alpha} J
$$

where $L=J M_{j}$ is the total labour force.

Taking into account equation 1 , we have: $\lambda\left(w_{j}\right)=\frac{b+w_{j}}{2}$, so $\lambda_{w_{j}}=\frac{1}{2}$. Substituting in 3, we obtain:

$$
n_{w_{j}}\left(\frac{1+\sigma_{j}}{1-\sigma_{j}} b-w_{j}\right)=n
$$


Substituting equation 5 and 6 into equation 8 we obtain the optimal wage paid by all firms in a pure monopsonistic framework with heterogeneous workers

$$
w_{j}^{*}=\frac{1}{3} \frac{b}{1-\sigma_{j}}+\frac{2}{3} R
$$

The equilibrium wage is a weighted average of the best workers' productivity and the reservation wage. Subsituting equation 9 in 5, 6, 7 we may obtain the equilibrium level of the labour force, employment, and unemployment rate.

Table 2 present some results concerning the effects of parameters on equilibrium levels.

table 2 about here

Some of the relations of table 2 are obvious, other are more difficult to be explained. For example, a positive shock raises labour force more than employment, increasing the unemployment rate; a reduction of transportation costs or a population growth raises both employment and labour force leaving unchanged the unemployment rate.

Such as in classical monopsony theory, a binding minimum wage may rise employment ${ }^{11}$. In our model, a minimum wage $(v)$ raise employment if $v \leq$ $\widetilde{w}_{j}=\min \left(\widehat{w}_{j}, R+\frac{\alpha}{J}\right)$, where $\widehat{w}_{j}$ is the classical condition in monopsonistic labour markets, that is the level of wage which maximizes the labour demand function $n\left(w_{j}\right)$ (see figure 2), and $R+\frac{\alpha}{J}$ depends on labour force participation. Given that $w_{j}^{*} \leq \widetilde{w}_{j}$, firms operate in a labour demand function upward sloping.

If the minimum wage is less than the critical value $\left(\widetilde{w}_{j}\right)$ :

Proposizione 2 For a given number of firms, the effects of the introduction of a minimum wages on a monopsony with heterogeneous workers are:

\section{Raising employment at firm level and at aggregate level}

\section{Enlarging the attraction basin of each firm and raising labour force}

\section{Raising both the unemployment rate and the participation rate.}

\footnotetext{
${ }^{11}$ The most complete analysis of the effect on the economic system of minimum wage law is presented in Card and Krueger, 1995. They “... present a new body of evidence showing that recent minimum wage increases have not had the negative effects predicted by the textbook model. Some of the new evidence points toward a positive effect of the minimum wage on employment...", page 2 .

The most recent review can be found in Boal and Ransom, 1997. See also Rebitzer and Taylor, 1993.
} 
Clearly, this analysis is correct when the number of firms is constant, that is when product market is oligopolistic, when entry thresholds exist or generally in the short run.

If we assume free entry condition firms enter until profits are positive and exit when negative. Substituting 9 in 2 we obtain that the level of profits in a monopsony with heterogeneous workers does not depend on the number of firms $J$

$$
\pi_{j}=\frac{2}{27} \mu \frac{(b-R)^{3}}{\alpha}-F
$$

Proposizione 3 If we suppose free entry of firms, monopsony cannot exist because:

- If $\pi<0$, all the firms exit.

- If $\pi>0$, firms enter up to equation 4 does not hold, thus monopsony change in a monopsonistic competition labour market.

\subsection{Monopsonistic competition with heterogeneous workers}

Assuming that equation 4 does not hold, then

$$
w>\frac{\alpha}{J(w)}+R
$$

where $J(w)$ indicates that now the number of firms is endogenous to the model. Let us calculate the labour force available to the $j-t h$ firm which pays a wage of $w_{j}$ when the outside wage paid by the other firms is $w$.

It is important to realise that, when a firm pays its workers more than the other firms, it faces a labour supply function that is different from that one calculate when it pays its workers less than the other firms.

Paying a wage above the average $\left(w_{j}>w\right)$, a firm attracts a bigger number of workers and recruits those workers whose individual productivity is higher than the wage ${ }^{12}$. So, a higher wage leads to higher average productivity of workers employed.

The employment in a firm that pays $w_{j}>w$ is indicate by the area $\mathrm{B}$ of figure 3. We can write ${ }^{13}$ :

$$
L_{j}\left(w_{j}, w\right)=\left(\frac{1}{J(w)}+\frac{w_{j}-w}{\alpha}\right) P
$$

\footnotetext{
${ }^{12}$ The same hypothesis has been proposed by Manning (1993).

${ }^{13}$ Following the same procedure used for monopsony, there is a person on point $B$ of figure 1 for whom it is indifferent to work in firm $I_{1}$ or in firm $I_{2}$. For this worker, the following equation must be valid: $w_{j}-\alpha \overline{I_{1} B}=w-\alpha \overline{I_{2} B}$. We can also write $\frac{w_{j}-w}{\alpha}=\overline{I_{1} B}-\overline{I_{2} B}$; the second term is equivalent to: $2 \overline{I_{1} B}-\overline{I_{1} I_{2}}$, the distance between the two firms $\left(\overline{I_{1} I_{2}}\right)$ could be written as $\frac{1}{J}$.
} 
The first term in equation 11 represents the share of labour force available to the firm when wages are the same for the whole economy and the second term is the way by which the firm could increase this share. A worker will decide to move to another firm, only if the net-income $\left(w_{j}-w\right)$ covers, at least, his increased travelling expenses.

Integrating the equation 11 we obtain the firm employment

$$
\tilde{n_{j}}\left(w_{j}, w\right)=\int_{w_{j}}^{b} \mu \frac{L_{j}\left(w_{j}, w\right)}{P} d \Lambda
$$

Given the distribution of labour force productivity, firms (the black points on the ring in fig. 1) compete on the labour market to hire the best workers offering wages which are higher than the reservation wage. In this case, the average productivity of the $j-t h$ firm is simply $\widetilde{\lambda}=\frac{b+w_{j}}{2}$.

On the contrary, if firm $j$ pays $w_{j}<w$, it loses a part of its higher productive workers which are hired by firms paying higher wages. However, it can use a monopsonistic power over those workers with productivity between $w_{j}$ and $w$. Employment is now given by area $\mathrm{C}$ of figure 3. In fact low productive workers cannot be employed by high wage firms but only by low wage ones and so they have to decide if work or not, having no possibility to decide where to work.

It is not difficult to show that employment in firm $j$ is:

$$
\begin{aligned}
\widehat{n_{j}}\left(w_{j}, w\right) & =n 1\left(w_{j}, w\right)+n 2\left(w_{j}, w\right)= \\
& =\int_{w}^{b} \mu \frac{L_{j}\left(w_{j}, w\right)}{P} d \Lambda+\int_{w_{j}}^{w} \mu \frac{M_{j}\left(w_{j}\right)}{P} d \Lambda
\end{aligned}
$$

where the first integral $\left(n 1\left(w_{j}, w\right)\right)$ gives the number of workers with productivity higher than $w$, while the second $\left(n 2\left(w_{j}, w\right)\right)$ represents those workers with productivity lower than $w$, which have to choose between being hired at a lower wage than the average wage, or being unemployed. The average productivity is:

$$
\widehat{\lambda}=\frac{n 1\left(w_{j}, w\right)}{\widehat{n}\left(w_{j}, w\right)} \frac{b+w}{2}+\frac{n 2\left(w_{j}, w\right)}{\widehat{n}\left(w_{j}, w\right)} \frac{w+w_{j}}{2}
$$

In the symmetric case, all firms have the same shock $\left(\sigma_{j}=\sigma \forall j\right)$. Substituting in equation 3 the definitions of $\widetilde{n}$, and $\widetilde{\lambda}$ we obtain the reaction function of firm $j$ when outside wages $(w)$ are smaller than the equilibrium wage $\left(w^{*}\right)$. While subsituting the definitions of $\widehat{n}$ and $\widehat{\lambda}$, we obtain the reaction function for outside wage higher than equilibrium one.

Proposizione 4 There is a unique fixed point for reaction functions, this fixed point is the nash-simmetric equilibrium wage $w^{*}$ which is stable ${ }^{14}$.

\footnotetext{
${ }^{14}$ Appendix 1 will demonstrate this proposition.
} 
In the short-run $J(w)=J$; the equilibrium wage is:

$$
w^{*}=\frac{b}{1-\sigma}-\frac{2 \alpha}{J}
$$

Let us analyse this equilibrium. The employment of each firm is:

$$
\widetilde{n}=\widehat{n}=n=\frac{\mu}{J}\left(\frac{2 \alpha}{J}-\frac{\sigma b}{1-\sigma}\right)
$$

Thus, a common positive shock $(\sigma>0)$ raises the equilibrium wage $\left(\frac{d w}{d \sigma}>0\right)$ but reduces firm employment $\left(\frac{d n}{d \sigma}<0\right)$. This result depends on the competition between firms. They try to hire more workers by raising their wage, but, given the symmetric behavior, workers with a productivity which is lower than the new wage will be fired, so that the employment level decreases.

According to Bhaskar and To, this situation may be defined "Oligopsony" in the labour market.

Proposizione 5 In an oligopsonistic labour market, the unemployment rate is increasing in job differentiation and it is decreasing in the variance of workers' productivity.

The complete derivatives of variables with respect to parameter are shown in table 3.

Since now we have considered a given, exogenous number of firms. However, contrary to the previous analysis, we could endogenise the number of firms. This will modify the previously results.

For the sake of simplicity we set $\sigma=0$. Perfect competition on the product market sets profits to zero; consequently we obtain from equation $2^{15}$ the endogenous number of firms as a function of the wage:

$$
J(w)=\frac{\mu(b-w)^{2}}{2 F}
$$

This enables us to find an equilibrium value of $w$ under the zero profit assumption . We obtain:

$$
w^{*}=b-2\left(\frac{\alpha F}{2 \mu}\right)^{\frac{1}{3}}
$$

\footnotetext{
${ }^{15}$ For $w_{j}=w$,
} 
We may calculate $J^{*}$, the number of firms compatible with the free entry condition.

$$
J^{*}=\left(2 \frac{\alpha^{2}}{F} \mu\right)^{\frac{1}{3}}
$$

From equation 15 it is easy to calculate employment in each firm:

$$
n^{*}=\left(\frac{2 \mu}{\alpha}\right)^{\frac{1}{3}} F^{\frac{2}{3}}
$$

The unemployment rate is simply given by:

$$
u^{*}=\frac{L-n^{*}}{L}=1-\left(\frac{2}{b-a}\right)^{\frac{2}{3}}\left(\frac{\alpha F}{P}\right)^{\frac{1}{3}}
$$

Unemployment is completely involuntary: the unemployed would like to work for current wages, but they are not hired because wages are an instrument used by firms in order to select the best workers. As we mentioned above, in this model, as in those with adverse selection, even in a setting where unemployment is high firms do not cut wages.

A wider range of productivity $(b-a)$ - i.e. stronger heterogeneity- worsens the economy's employment performance. Moreover, a reduction in travelling expenses $\alpha$, (or, more generally, a reduction in job differentiation) increases the unemployment rate because the power of wage, as a tool to enlarge the actraction basin, becomes stronger.

So, according to this framework, countries with more homogeneous workers and less job differentiation should have lower wages and a lower unemployment rate.

table 3 about here

In a free entry economy, where firms earn no profit, the minimum wage will induce firms to exit and consequently it leads to changes in the endogenous number of firms. In the long run, substituting the number of firms (equation 16) in equation 15 , we obtain

$$
n=\frac{2 F}{b-w}
$$

that is an upward sloping relation between employment at firm level and wages.

The total employment and the unemployment rate are respectively: $n J=$ $\frac{b-w}{b-a} P$ and $u=1-\frac{b-w}{b-a}$. 
Proposizione 6 In the long run, the effects of minimum wages on a monopsonistic competition economy with heterogeneous workers are:

1. Raising employment at firm level.

2. Reducing the number of firm, because of equation16.

3. Reducing total employment, because the reduction of the number of firms $J$ is greater than the increase in firm employment.

4. Raising the unemployment rate.

\section{Unemployment versus market segmentation}

There could be some social norms, or institutional rules which definitively forbid firms to pay a wage lower than $w$. In this case the dynamics of the labour market would immediately end up, and the previous results could be seen as a steady state solution.

In the absence of these norms, an intriguing question arises: why don't new firms enter the market, exploiting the unemployed workers and paying them a lower wage?.

In other words we wonder why people do not flow towards a secondary sector characterized by a lower wage and lower productivity. If this possibility exists and it is economically convenient, the labour market will be segmented in two or more sub-markets.

Let we label each segment of the market with an $i$, ranking from the most to the least productive segment; segment $i$ hires a certain number of workers, paying a wage of $w_{i}{ }^{16}$.

Each segment chooses the wage and, consequently, the number of workers, by using the same reasoning of the most productive segment $(i=1)$. The only difference is that the new firms know that the range of productivity is no longer between $a$ and $b$, since the upper segment of firms has already hired those with productivity between $\left(w_{i}\right)$ and $b$. Therefore we should integrate equation [12 or 13] between $w_{i+1}$ and $w_{i}$, where $w_{i+1}$ is the optimum wage rate resulting from profit maximization of the $i+1-t h$ segment. This behavior continues until condition 10 holds.

In fact, if the higher productivity workers are employed in firms of a higher segment, workers disposable for lower segments decrease. The firm's attraction power becomes weaker and weaker because of wage decreasing. Monopsonistic competion is a faisible market structure only if all workers are able to reach any

\footnotetext{
${ }^{16}$ For the first segment $(i=1)$ all the results of the previous section hold.
} 
firm to offer their skills. In fact, it is possible that some workers have to bear transportation costs higher than the benefits of wage. Moreover firms face another constraint on supply side, since the demand of labour must be less then supply.

Therefore, two constraint must apply for market segmentation:

1. $w_{i}>\frac{\alpha}{J}+R$

2. $L_{j} J_{i} \geq \sum_{i} n_{i j} J_{i}$

The first one states that all workers are disposal to participate to labour force; as soon as it does not apply market structure changes from monopsonistic competition to pure monopsony. The second states that the demand for labour is less than the supply ${ }^{17}$. Let us define $i^{*}$ as the last segment for which both conditions hold. In this case the existence of another segment $\left(i^{*}+1\right)$ depends on the possibility to have a pure monopsonistic segment for the lowest productive workers.

As we show in the appendix 2, when the first condition does not hold anymore, monopsony profits are negative. Therefore we could exclude the existence of a pure monopsony segment. While, if the second constraint is binding, we have no unemployment and in the last segment the wage is set equal to the lower bound productivity $a$.

The relative strenght of two constraints depends on parameters.

As we prove in appendix 2:

Proposizione 7 With free entry in the long run, a monopsonistic segment cannot exist; the involuntary unemployment is a possible result even with secondary labour market

This situation could not necessarily be considered as "marginal": there may be very few segments, particularly when the variance of the productivity distribution is low; in this case the share of workers who cannot be employed may be large. The unemployment is involuntary since workers are willing to work both at current and at lower wages, but there is no incentives for firms to segment the labour market.

The number of segments characterised by monopsonistic competition is

$$
i<-\frac{1}{2}+\frac{1}{2} \frac{b-R}{\alpha} J^{*}=\frac{b-R}{2}\left(\mu \frac{2}{\alpha F}\right)^{\frac{1}{3}}-\frac{1}{2}
$$

where $J^{*}$ is the long-run number of firms in each segment which is a constant $J^{*}=\left(2 \frac{\alpha^{2}}{F} \mu\right)^{\frac{1}{3}}$. So the number of segments is increasing with the variance of productivity and decreasing with transportation and fixed costs.

\footnotetext{
${ }^{17}$ Note that the total labour force does not change, so $L_{i, j} J_{i}=L_{k, j} J_{k}, \forall i, \forall k$
} 
It is easy to demonstrate that in the long-run equilibrium each segment has the same number of firms $J^{*}$ and employs the same number of workers $n^{*}=$ $\left(\frac{2 \mu}{\alpha}\right)^{\frac{1}{3}} F^{\frac{2}{3}}$, while a represantative firm of the $i-t h$ segment pays a wage $w_{i}=b-$ $2 i\left(\frac{\alpha F}{2 \mu}\right)^{\frac{1}{3}}$ which is decreasing with the number of segments. The unemployment rate is

$$
u=1-i \frac{n^{*} J^{*}}{L^{*} J^{*}}=1-i\left(\frac{2}{b-a}\right)^{\frac{2}{3}}\left(\frac{\alpha F}{P}\right)^{\frac{1}{3}}
$$

Substituting equation 21 , we obtain that

$$
u \geq \frac{1}{2}\left(\frac{2}{b-a}\right)^{\frac{2}{3}}\left(\frac{\alpha F}{P}\right)^{\frac{1}{3}}-\frac{a-R}{b-a}
$$

which reverts some of the results of table 2 (see equation 20) since the unemployment increases with transportation costs and with fixed costs, decreases with population, moreover it decreases with the difference between the lower bound of productivity and reservation wage; finally the effects of the productivity gap is ambiguous $^{18}$.

Proposizione 8 Labour market segmentation does not eliminate unemployment, but it reverts the relation between the unemployment rate and the parameters.

For istance if the parameter $\alpha$ decreases, unemployment rate increases (see table 2), but it exists a threshold level of $\alpha$ that leads a new segment enters the market and it decreases unemployment (see figure 4). The same discontinuity effects characterise the other parameters.

figure 4 around here

What happens if a minimum wage is set by goverment in an economy as described above? We may distinguish two different effects:

- effects on the lowest productivity segment

- effects on the number of segments

Both effects reduce the employment, because of proposition 6.

Proposizione 9 With free entry of firms, market segmentation does not modify the negative impact of minimum wage on labour market.

\footnotetext{
${ }^{18} u$ is increasing in $b$ if $b<a+\frac{27}{4} P \frac{(a-R)^{3}}{\alpha F}$
} 


\section{Concluding Remark}

The model presented in this paper is conceived in order to evaluate the effect that differences in both workers' productivity and job characteristics ${ }^{19}$ may generate in a labour market equilibrium. We have assumed that all the workers employed in a firm must earn the same wage, even if firms know that they have different productivity levels. On the other hand we allowed for segmentation in the labour market, so that firms in different segments may pay different wages for the same job.

Differences in job characteristic make labour supply for an individual firm not perfectly elastic: the wage becomes a choice variable for firms. In this situation, firms may compete for hiring the best workers. In fact, each firm has monopsonistic power: higher wages lead to a better composition of the labour force.

Without free entry, firms can face two alternative labour market structures, pure monopsony or oligopsony, depending on the number of firms. In both cases unemployment exists since firms use wages in order to select workers. The less productive workers will not be hired even if they are willing to work for wages below the equilibrium level, thus involuntary unemployment is a crucial result of our model.

Firms entry leads to monopsonistic competition, where firms compete for the best workers, raising the wage above its market clearing equilibrium (i.e., above the reservation wage).

Monopsonistic competition is justified in a simple game framework where firms take the outside wage as given.

Endogenising the number of firms on a zero profit condition base, we obtain some interesting results (see table 4). In particular, an increase in the variance of productivity distribution and a decrease in travelling expenses raise the unemployment rate, reverting the results of oligopsony.

Finally we allow for endogenous market segmentation; other firms can enter the market and pay lower wages by hiring the less productive workers ${ }^{20}$. This reduces unemployment or may completely eliminate it.

In any case the impact of minimum wage on unemployment rate is negative, in particular in pure monopsony a minimum wage reduces unemployment but increa-

\footnotetext{
${ }^{19}$ In our model localisation causes job characteristic.

${ }^{20}$ Using our model, we seem to interpret the difference in labour market segmentation and the unemployment rate between USA and Europe. The former is characterized by a more segmented labour market, that is to say a greater difference in wage structure than the latter. On the contrary, Europe suffers higher unemployment. Throughout the 1970s and 1980s wage differentials widened in the United States but not in Europe, where marginal labour force groups experienced increasing and persistent unemployment.
} 
ses labour force, augmenting unemployment rate; in monopsonistic competition, with or without segmentation, minimum wage reduces employment.

Our work represents a first attempt in the analysis of the double heterogeneity that considers different non-wage characteristic and different workers productivity levels.

In our framework, we have considered well-informed firms. They know perfectly the productivity of each worker. In this way we pointed out the role of heterogeneity in explaining the dynamic of labour in a nearly "adverse selection" model.

It would be interesting to investigate a framework with imperfect information about individual productivity and with turnover rates of workers. In this case, firms do not know ex-ante workers' productivity. Thus, there may be an unemployed worker with a productivity which is higher than the prevailing wage. Furthermore, attracting workers in a secondary sector will be more difficult in an incomplete information framework than in a perfect knowledge one. 


\section{Riferimenti bibliografici}

[1] Akerlof G. (1982); "Labour Contracts as Partial Gift exchange", The Quarterly Journal of Economics, No. 4, November 1992, pp. 543-569

[2] Bhaskar V and To T. (1996) "Minimum Wages for Ronald McDonald Monopsonies: A Theory of Monopsonistic Competition", Unpublished paper, Department of Economics, University of Saint Andrews, Saint Andrew

[3] Boal W.M. and Ransom R. (1997); "Monopsony in the Labor Market", Journal of Economic Literature, No. 35 (1), pp. 86-112

[4] Card D. and Krueger A.B. (1995); Myth and Measurement: The New Economics of The Minimum Wage; Princeton University Press, Princeton

[5] Frank R. (1985) "Choosing the right Pond", Oxford University Press, New York

[6] Manning A. (1993); "Labour Markets with Company Wage Policy"; Unpublished Paper, LSE.

[7] Rebitzer J.B. (1989); ’Unemployment, Long-term Employment Relations and the Determination of Unit Labour Cost Growth in U.S. Manufacturing Industries", International Review of Applied Economics; 3(2), June 1989, pp. $125-47$

[8] Rebitzer J.B and Taylor L.J. (1993) "The Consequences of Minimum Wage Laws. Some New theoretical Ideas", Journal of Public Economics, No. 56, pp. $245-255$

[9] Weiss A. (1980); "Job Queues and Layoff in Labor Markets with Flexible Wages"; Journal of Political Economy, No. 88 (3), 526-38

\section{Appendix 1 -}

Case 1: $w_{j} \geq w ; w \geq \frac{\alpha}{J}+R$

If firm $j$ pays wages above the average, substituting equation 12 in equation 8 , the firm chooses the level of wage $\left(w_{j}\right)$ that maximizes its profit under the constraint $L\left(w_{j}, w\right) \geq n_{j}\left(w_{j}, w\right)$. When the constraint is not binding, we obtain a sort of reaction function:

$$
w_{j}=\frac{1}{3}\left(\frac{b}{1-\sigma_{j}}+2 w-\frac{2 \alpha}{J(w)}\right)
$$


where $\sigma_{j}$ is an idiosyncratic shock at firm level. ${ }^{21}$. Imposing simmetry between firms, we have the equilibrium wage for the economy: $w^{*}=\frac{b}{1-\sigma}-\frac{2 \alpha}{J}$

The relation between $w_{j}$ and $w$ is convergent because $\frac{d w_{j}}{d w}=\frac{2}{3}$.

Case 2: $w_{j}<w ; w \geq \frac{\alpha}{J}+R$

If firm $j$ decides to pay wages below the outside wage, its employment (13) is given by

$$
n\left(w_{j}, w\right)=n 1\left(w_{j}, w\right)+n 2\left(w_{j}, w\right)
$$

where:

$$
\begin{gathered}
n 1\left(w_{j}, w\right)=\int_{w}^{b} \mu\left(\frac{1}{J}+\frac{w_{j}-w}{\alpha}\right) d \Lambda \\
n 2\left(w_{j}\right)=\int_{w_{j}}^{w} \mu \frac{w_{j}-R}{\alpha} d \Lambda
\end{gathered}
$$

So: $n 1\left(w_{j}, w\right)=\mu(b-w)\left(\frac{1}{J}+\frac{w_{j}-w}{\alpha}\right)$ and $n 2\left(w_{j}, w\right)=\mu\left(w_{j}-w\right) \frac{w_{j}-R}{\alpha}$

It is now possible to calculate the average productivity of workers employed in the $j-t h$ firm:

$$
\lambda=\frac{n 1}{n} \frac{b+w}{2}+\frac{n 2}{n} \frac{w_{j}+w}{2}
$$

In order to define the otpimal value for the wage $w_{j}$, we substitute the value for $n$ and $\lambda$ in equation 3 (for the sake of simplicity let us set the shock: $\sigma=0$ ):

$$
w_{j}(w)=\frac{2 b+R-\sqrt{(R+b)^{2}+2 R\left((b-3 w)+6(b-w)\left(\frac{\alpha}{J}-w\right)\right.}}{3}
$$

that is the reaction function of firm $j$ when its own wage is lower than outside wages.

Imposing simmetry between firms, so $w_{j}=w$, for $a \leq w<b$ we obtain the unique equilibrium wage: $w^{*}=b-\frac{2 \alpha}{J}$, that is the same obtained in case 1 for $\sigma=0$. Let's analyse the caracteristic of this fixed point. Rememer that we are

\footnotetext{
${ }^{21}$ Equation 22 is the approximate solution, obtained by imposing second order terms containing $\sigma$ to be equal to zero. Nevertheless, for $\sigma=0$ [22] is the exact solution.
} 
analysing situation in which $R+\frac{\alpha}{J} \leq w<b$; differentiating equation 23 and calculating the derivates at the extreme, we obtain:

$$
\left.\frac{d w_{j}}{d w}\right|_{w=R+\frac{\alpha}{J}}=1-\frac{\alpha}{J} \frac{1}{b-R}<1
$$

and

$$
\left.\frac{d w_{j}}{d w}\right|_{w=b}=\frac{\alpha}{J} \frac{1}{b-R}-1>-1
$$

So the absolutevalue of the first derivative is less than one at the extrema. We remind that $w \geq \frac{\alpha}{J}+R$, then

$$
-1<\left.\frac{d w_{j}}{d w}\right|_{w=b}<0<\left.\frac{d w_{j}}{d w}\right|_{w=R+\frac{\alpha}{J}}<1 .
$$

Moreover, it is possible to demonstrate that $\left(\frac{\left(d w_{j}\right)^{2}}{d^{2} w}\right)<0$. Then we demostrated that the first derivative is always decreasing for $R+\frac{\alpha}{J} \leq w<b$ and $-1<\frac{d w_{j}}{d w}<$ +1 . So $w=w^{*}$ is an actractive fixed point of 23 .

\section{Appendix 2 -}

Two constraint must apply for market segmentation:

1. $w_{i}>\frac{\alpha}{J}+R$

2. $L_{j} J_{i} \geq \sum_{i} n_{i j} J_{i}$

where $i$ indicates the segment of market.

When the second constraint is binding, the profit is maximized by $w_{i^{*}+1}=a$. The number of firms that makes profits equal to zero in the segment where the second constraint is binding is

$$
J_{i^{*}+1}=\frac{\left(w_{i^{*}}-a\right)^{2}}{2 F} \frac{P}{b-a}
$$

since $\left(w_{i^{*}}-a\right)<\left(w_{i-1}-w_{i}\right)$ it is easy to demonstrate that $J_{i^{*}+1}<J_{i^{*}}$, so the last segment of the labour market is characterized by a smaller number of firms. The employment of a single firm of that segment is:

$$
n_{i^{*}+1}=\frac{2 F}{w_{i^{*}}-a}
$$


which is greater than $n_{i^{*}}$. Total employment in the last productive market segment is lower than that in other segments. Note that it means that there is no involuntary employment.

Until both the constraints are not binding we can derive the wages paid by each segment, the number of employed workers and the whole economy's unemployment in a recursive way.

For a given number of firm, the long-run symmetric equilibrium wage of $i-t h$ segment is:

$$
w_{i}=b-i \frac{2 \alpha}{J^{*}}=b-2 i\left(\frac{\alpha F}{2 \mu}\right)^{\frac{1}{3}}
$$

The number of workers hired by a firm of the $i-t h$ segment, is simply the symmetric equilibrium of the equation [12 and 13], integrated between $w_{i-1}$ and $w_{i}$ :

$$
n_{i}=\frac{\mu}{J}\left(w_{i-1}-w_{i}\right)
$$

Since the difference between the wages of two close segments is constant:

$$
\left(w_{i-1}-w_{i}\right)=2^{\frac{2}{3}}\left(\frac{\alpha F}{\mu}\right)^{\frac{1}{3}}
$$

$n_{i}$ is constant:

$$
n^{*}=\left(\frac{2 \mu}{\alpha}\right)^{\frac{1}{3}} F^{\frac{2}{3}}
$$

Each firm in each segment will hire the same number of workers but workers will have a lower productivity and firms will pay less for them. Substituting 24 in 10 we can calculate for each segment the number of firms $\left(J_{-} s_{i}\right)$ under which the first constraint starts being effective:

$$
J_{\_} s_{i}=\frac{3 \alpha}{w_{i-1}-R}=\frac{1+2 i}{b-R} \alpha
$$

which is increasing with the number of segments. Until the number of segments grant that 10 is valid, $J^{*}>J_{-} s_{i}$; thus labour market is characterised by monopsonistic competition and wages are set along equation [24].

However, it is highly possible that for the segment $\left(i^{*}+1\right)$ the condition 10 does not hold, in this case the $i^{*}+1$ segment is a pure monopsonistic market. 
Firms in $\left(i^{*}+1\right)$ segment set their wages integrating [5] from $w_{i^{*}+1}$ and $w_{i^{*}}$. For profit maximisation

$$
w_{i^{*}+1}=\frac{1}{3} w_{i^{*}}+\frac{2}{3} R
$$

Monopsonistic profit of segment $\left(i^{*}+1\right)$ is positive if

$$
\frac{2}{27} \mu \frac{\left(w_{i^{*}}-R\right)^{3}}{\alpha}>F
$$

But conditions 10 does not hold if

$$
\begin{gathered}
J^{*}<J_{-} s_{i^{*}+1} \\
\left(2 \frac{\alpha^{2}}{F} \mu\right)^{\frac{1}{3}}<\frac{3 \alpha}{w_{i^{*}}-R}
\end{gathered}
$$

then, after some simple manipulations, we obtain:

$$
\frac{2}{27} \mu \frac{\left(w_{i^{*}}-R\right)^{3}}{\alpha}<F
$$

this proves that when $J^{*}<J_{-} s$, there are no rooms for a pure monopsonistic market. $^{22}$

Finally, substituting the equilibrium values in the constraints we may calculate which one is effective.

$$
\begin{gathered}
b-R \geq\left(\frac{\alpha F}{2 \mu}\right)^{\frac{1}{3}}(1+2 \widetilde{i}) \\
1 \geq 2 \widehat{i} \frac{P}{b-a}\left(\frac{\alpha F}{2 \mu}\right)^{\frac{1}{3}}
\end{gathered}
$$

Solving for $i$ :

$$
\widetilde{i} \leq \frac{b-R}{2}\left(\frac{2 \mu}{\alpha F}\right)^{\frac{1}{3}}-\frac{1}{2}
$$

\footnotetext{
${ }^{22}$ An intriguing question arise when $J^{*}>J_{-} s_{i^{*}+1}$ but $J_{-} s>J_{i^{*}+1}$. In this case if firms pays wages equal to $a$, there are some workers which considers the firms too far, then pure monopsony conditions hold. We leave this case to further analysis, since in the model presented we may argue that it is a very particular case.
} 


$$
\widehat{i} \leq \frac{1}{2 \mu}\left(\frac{2 \mu}{\alpha F}\right)^{\frac{1}{3}}
$$

If $\widehat{i}<\widetilde{i}$ the second constraint is more effective and market segmentation make unemployment disappear, on the contrary if $\widehat{i}>\widetilde{i}$ the first constraint must apply and unemployment persists. ${ }^{23} . \widehat{i}<\widetilde{i}$ means:

$$
\frac{1}{2}<\frac{1}{2}\left(b-R-\frac{b-a}{P}\right)\left(\frac{2 \mu}{\alpha F}\right)^{\frac{1}{3}}
$$

let us write $a=R+d>R$

$$
1<\left((b-R)\left(\frac{P-1}{P}\right)+\frac{d}{P}\right)\left(\frac{2 \mu}{\alpha F}\right)^{\frac{1}{3}}
$$

for high values of $P$ we have $\frac{P-1}{P} \simeq 1$ and $\frac{d}{P} \simeq 0$, then

$$
1<(b-R)\left(\frac{2 \mu}{\alpha F}\right)^{\frac{1}{3}}
$$

then $\widehat{i}<\widetilde{i}$ for

$$
b>R+\left(\frac{\alpha F}{2 \mu}\right)^{\frac{1}{3}}
$$

\footnotetext{
${ }^{23}$ We do not consider the case when $\widehat{i}<\widetilde{i}$, but floor $(\widehat{i})=$ floor $(\widetilde{i})$, since it is a marginal case.
} 


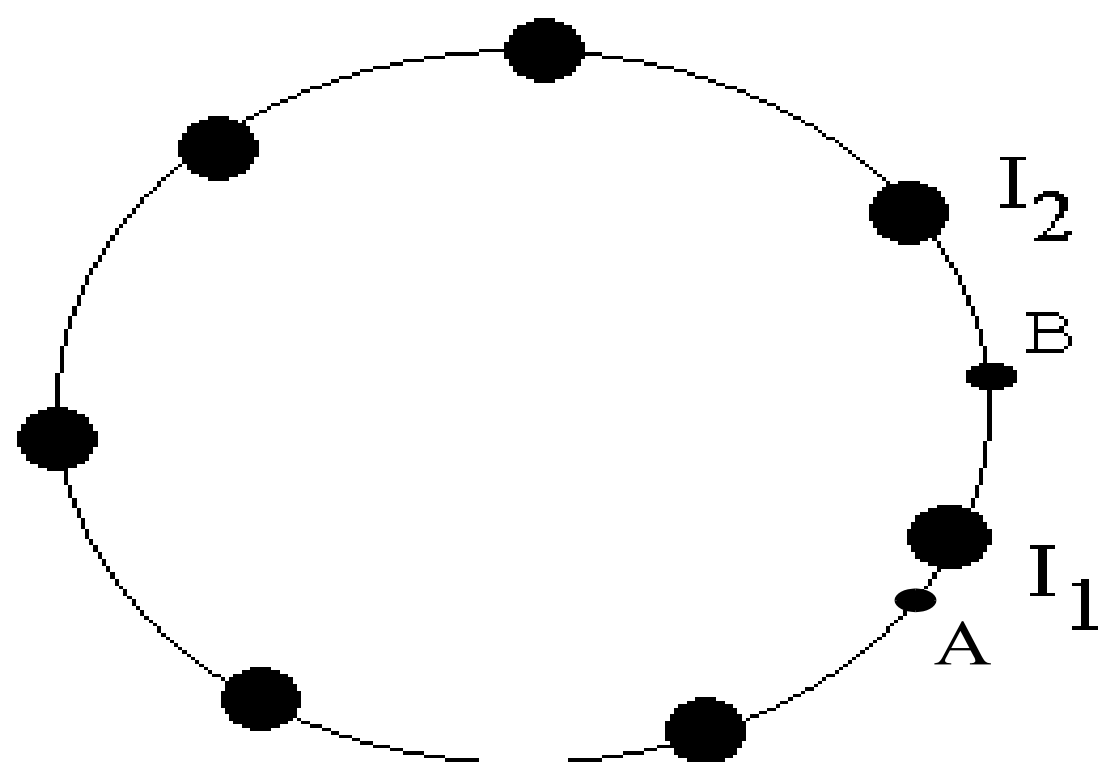

Figura 1: Firms and workers in a "ring" economy 


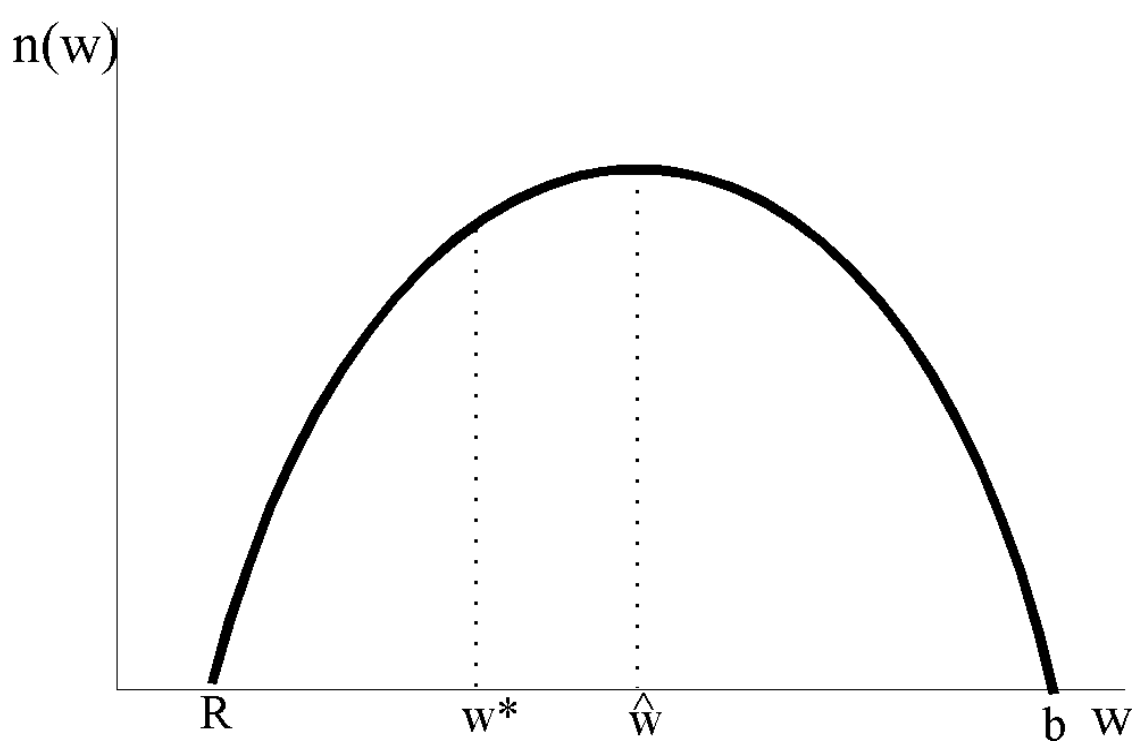

Figura 2: The demand for labour of a monopsonistic firm

Table 1

\begin{tabular}{|c|c|c|c|}
\hline \multicolumn{2}{|l|}{} & \multicolumn{2}{|c|}{ Firm 2 } \\
\hline & & $v$ & $w$ \\
\hline Firm 1 & $v$ & $1+2 \varepsilon, 1+2 \varepsilon$ & $2 \varepsilon, 2(2-w)$ \\
\hline & $w$ & $2(2-w), 2 \varepsilon$ & $2-w, 2-w$ \\
\hline
\end{tabular}

Table 2: derivatives on monopsony

\begin{tabular}{|l|l|l|l|l|l|}
\hline & $(b-a)^{*}$ & $\alpha$ & $R$ & $P$ & $\sigma$ \\
\hline impact of parameter on wages & + &. & + &. & + \\
\hline impact of parameter on total employment & - & - & - & + &. \\
\hline impact of parameter on total labour force & + & - & - & + & + \\
\hline impact of parameter on unemployment rate & + &. & + &. & + \\
\hline
\end{tabular}

Table 3: derivatives on oligopsony

\begin{tabular}{|c|c|c|c|c|}
\hline & $(b-a)$ & $J$ & $\alpha$ & $P$ \\
\hline impact of parameter on wages & + & + & - &. \\
\hline impact of parameter on firm employment & - & - & + & + \\
\hline impact of parameter on total employment & - & - & + & + \\
\hline impact of parameter on unemployment rate & - & - & + &. \\
\hline
\end{tabular}

Table 4: derivatives on monopsonistic competition 


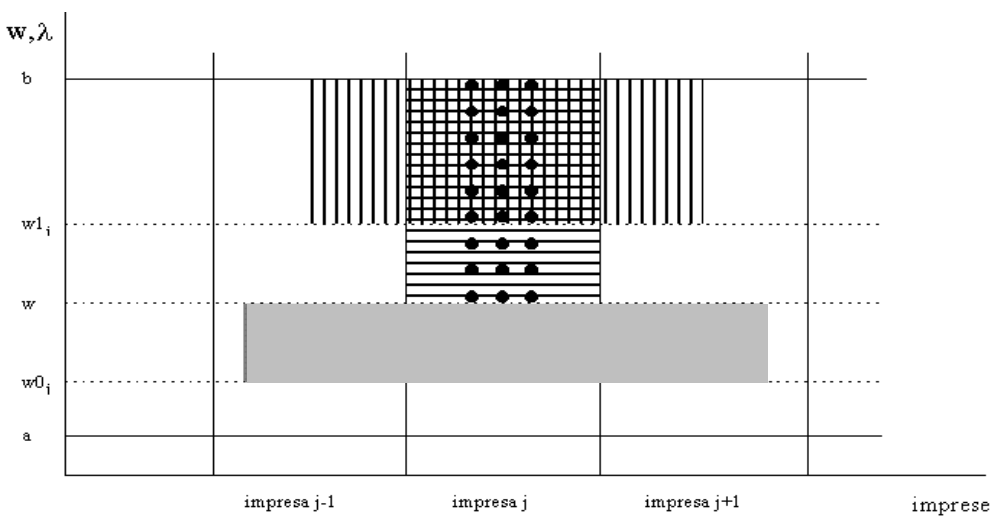

area $A: n=\equiv \quad w_{i}=w$

area $B: n=\prod \quad w_{i}>w$

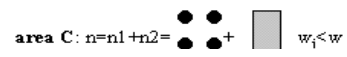

Figura 3: Employment in firm $J$ with monopsonistic competition

\begin{tabular}{|c|c|c|c|c|}
\hline & $(b-a)$ & $F$ & $\alpha$ & $P$ \\
\hline impact of parameter on wages & - & - & - & + \\
\hline impact of parameter on firm employment & - & + & - & + \\
\hline impact of parameter on the number of firms & - & - & + & + \\
\hline impact of parameter on unemployment rate & + & - & - & + \\
\hline
\end{tabular}

